\title{
CASE REPORT - ACUPUNCTURE TREATMENT IN FEMALE PATIENT PRESENTED WITH PRIMARY HYPOTHYROIDISM
}

\author{
Blagica Arsovska ${ }^{1,2}{ }^{\square}$, Jihe Zhu ${ }^{1}$, Kristina Kozovska ${ }^{1,3}$ \\ ${ }^{1}$ Faculty of Medical Sciences, University Goce Delchev, Shtip, Republic of Macedonia; \\ 2 Institute of Biology, Faculty of Natural Sciences and Mathematics, Skopje, Republic of Macedonia \\ ${ }^{3}$ Medicine Faculty, St. Cyril and Methodius University of Skopje, Republic of Macedonia
}

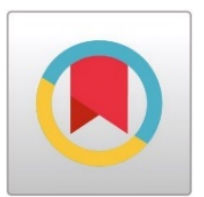

DOI: https://doi.org/10.29121/granthaalayah.v8.i6.2020.427

Article Type: Case Study

Article Citation: Blagica Arsovska, Jihe Zhu, and Kristina Kozovska. (2020). CASE REPORT ACUPUNCTURE TREATMENT IN FEMALE PATIENT PRESENTED WITH PRIMARY HYPOTHYROIDISM. International Journal of Research GRANTHAALAYAH, 8(6), 71-74. https://doi.org/10.29121/granthaa layah.v8.i6.2020.427

Received Date: 02 May 2020

Accepted Date: 21 June 2020

Keywords:

Traditional Chinese medicine Acupuncture

Thyroid

Endocrinology

\begin{abstract}
Primary hypothyroidism occurs due to increased thyroid-stimulating hormone (TSH). Most commonly it's autoimmune and results from Hashimoto's thyroiditis, which is also often associated with a firm goiter. In the primary hypothyroidism, the thyroid is being stimulated properly, but it's not able to produce enough thyroid hormones so the body can function normally. This means that the source of the problem is the thyroid itself. In this research is presented a case of a 33 year old woman diagnosed with primary hypothyroidism. The patient has done 34 acupuncture treatments in a period of 8 months. After 6 months of starting the treatment the patient medicament therapy with Euthirox was ended. The anti-TPO levels were decreased from 425 to $70.3 \mathrm{IU} / \mathrm{ml}$ and the TSH and fT4 levels were effectively kept within the normal range. Acupuncture treatment as part of the Traditional Chinese Medicine can be exceptionally effective in the treatment of primary hypothyroidism, although as a treatment for autoimmune disease it takes more time to see the positive results. Considering that it is an autoimmune and chronic disease, treatment also requires a long-term approach. The patient's condition will be monitored and treatments will be continued until complete normalization of the antiTPO levels.
\end{abstract}

\section{INTRODUCTION}

Primary hypothyroidism occurs due to increased thyroid-stimulating hormone (TSH). Most commonly it's autoimmune and results from Hashimoto's thyroiditis, which is also often associated with a firm goiter. In the primary hypothyroidism, the thyroid is being stimulated properly, but it's not able to produce enough thyroid hormones so the body can function normally. This means that the source of the problem is the thyroid itself. [1] [2]

Some patients that have had hyperthyroidism (overactive thyroid) may go to hypothyroidism because of the treatment with radioactive iodine. Other causes for hypothyroidism may be: congenital disease, autoimmune diseases, insufficient dietary iodine, viral thyroiditis or certain drugs. Some women might develop hypothyroidism after giving birth. [2]

Signs and symptoms of hypothyroidism are: weight gain, irregular menstrual cycles, infertility, skin "puffiness", periorbital edema, tiredness, dry skin, dry nails, hair loss, constipation, cold intolerance, depression, mood changes, poor memory and other. [3]

(C) 2020 The Author(s). This is an open access article distributed under the terms of the Creative Commons Attribution License, which permits unrestricted use, distribution, and reproduction in any medium, provided the original author and source are credited. 
Hypothyroidism is diagnosed via blood test by analyzing the thyroid hormones - T3, T4 and TSH. An elevated TSH level indicates that there is a thyroid problem (primary hypothyroidism). [2]

The Traditional Chinese Medicine (TCM) has a different approach than the Western Medicine. The TCM treatment for primary hypothyroidism includes long-term acupuncture and herbal medicine treatment. In TCM, hypothyroidism is classified as a Qi, yin or yang deficiency syndrome, usually of the Kidney.

Acupuncture treatment can help in regulating and tonifying the Qi and yang; vitalizing the blood and stimulating and strengthening the immune system. [4]

\section{CASE REPORT}

In this research is presented a case of a 33 year old woman diagnosed with primary hypothyroidism. The diagnosis was made one year before starting the acupuncture treatment. At the time when the patient has been diagnosed with primary hypothyroidism, she has also reported having strange thoughts and has visited several psychologists. The patient was prescribed Lunerba tablets, one tablet per day. For the thyroid for one year the patient was taking Eutirox $75 \mathrm{mg}$ per day.

The patient has a very hyperactive character, with normal gynecological findings and no visible symptoms, except the positive familial history of hyperthyroidism.

The patient has done 34 acupuncture treatments in a period of 8 months. The treatments were done in a clinic for acupuncture and TCM in Skopje, Macedonia by a doctor specialist in acupuncture. Treatments were done once a week, with duration of 30-45 minutes each side of the body. Treatments were done indoor, on a room temperature. In the treatment were used fine sterile disposable needles sized $0.25 \times 25 \mathrm{~mm}$ manufactured by Wuijuiang City Medical \& Health Material Co., LTD.

Acupuncture points used in the treatment are: RN4 (QuanYuan), RN6 (QiHai), DU20 (BaiHui), GB20 (FengChi), DU14 (DaZhui), LI4 (HeGu), DU4 (MingMen), BL15 (XinShu), ST9 (RenYing), BL20 (PiShu), BL23 (ShenShu), LR2 (TaiChong), SP9 (YinLingQuan), SP6 (SanYinJiao), ST36 (ZuSanLi) and KI3 (TaiXi). In the treatment were also included Ashi points located on the neck (front and back).

After 6 months of starting the treatment the patient medicament therapy with Euthirox was ended. During the treatments the patients has done three blood tests and one ultrasound image of the thyroid gland.

The interpretation of the thyroid ultrasound image (shown on figure 1) is - in general discreetly nonhypoehogenic, inhomogeneous with dimensions left lobe 16.1 x $12.7 \mathrm{~mm}$ and right lobe 16.8 x $12.2 \mathrm{~mm}$.

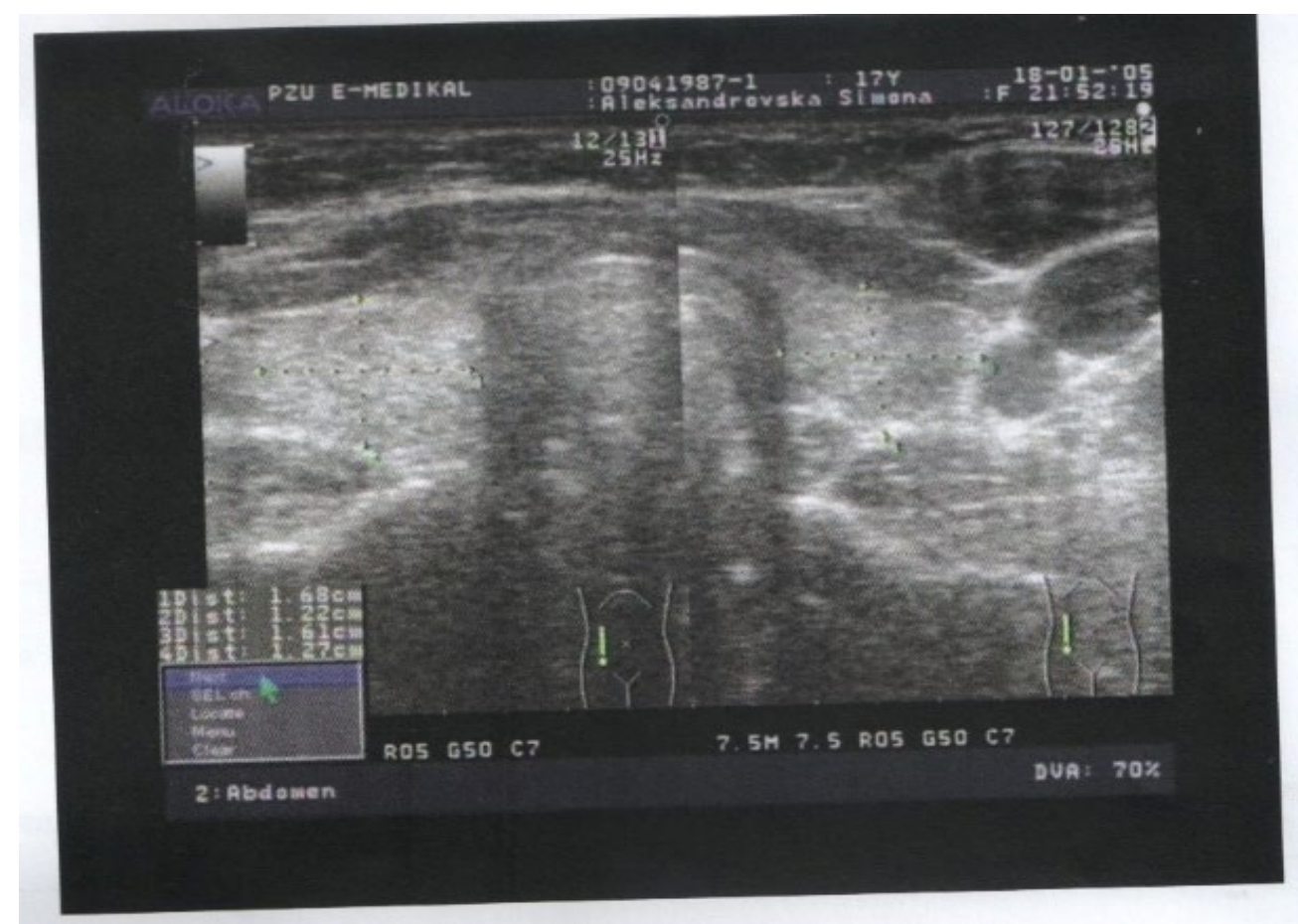

Figure 1: Ultrasound image of the thyroid gland done one month after starting the treatment 
Table 1: Blood tests done before starting the treatment, during and after the treatment

\begin{tabular}{|l|c|c|c|c|}
\hline Date & $\begin{array}{c}\text { TSH }(0.45-5.33 \\
\mathrm{IU} / \mathrm{ml})\end{array}$ & $\begin{array}{c}\mathrm{fT} 4(10.6-19.4 \\
\mathrm{pmol} / \mathrm{l})\end{array}$ & $\begin{array}{c}\text { Anti-TPO }(10-50 \\
\mathrm{IU} / \mathrm{ml})\end{array}$ & $\begin{array}{c}\text { ATG }(20-40 \\
\mathrm{IU} / \mathrm{ml})\end{array}$ \\
\hline Before treatment & 16.05 & 10.26 & $/$ & $/$ \\
\hline $\begin{array}{l}\text { During the } \\
\text { treatment }\end{array}$ & 3.35 & 19.3 & 425 & 92 \\
\hline After the treatment & 5.34 & 11.66 & 70.3 & $/$ \\
\hline
\end{tabular}

Within the 8 months of acupuncture treatment, 3 control blood tests were made. The results from the blood teste are shown on table 1 . After 6 months of treatment the medical therapy was stopped and the patient continued only with the acupuncture treatment. The last test was made after the $34^{\text {th }}$ acupuncture treatment ( 8 months) without taking any additional medications. During that period the anti-TPO levels were decreased from 425 to 70.3 $\mathrm{IU} / \mathrm{ml}$ and the TSH and fT4 levels were effectively kept within the normal range. In spite of the good and satisfying results, the patient will continue with the treatments until the anti-TPO and TSH levels are totally normalized. Considering that it is an autoimmune and chronic disease, treatment also requires a long-term approach.

When the ATG (antithyroglobulin antibody) test is showing increased numbers as in this case, an autoimmune condition is suspected. An autoimmune condition can disrupt the production of thyroglobulin and make the immune system create antibodies that attack the body's own healthy cells. When the immune system attacks the thyroid, it often targets thyroglobulin and it causes production of antithyroglobulin antibodies. Indicated autoimmune diseases are Graves' disease or Hashimoto thyroiditis. [5]

Over $95 \%$ of the total hypothyroidism cases are primary hypothyroidism and over 90\% of the primary hypothyroidism cases are caused by autoimmune thyroid diseases. [6]

According to the TCM, there are three possible syndromes for hypothyroidism: Heart and Kidney yang deficiency, Spleen and Kidney qi deficiency and Kidney yin deficiency. However, the main affected organ is the Kidney and the Heart is more involved in the advanced stages. [7] [8]

The aim of the acupuncture treatment is to strengthen the Qi and yang deficiency, replenish the yang Qi, warm and remove the blockages from the meridians, recharge and tonify the affected organ system, improve the thyroid gland function, balance the energy in the body and awaken the body's natural ability to heal on its own. [7] [8] [9]

\section{CONCLUSION}

Acupuncture treatment as part of the Traditional Chinese Medicine can be exceptionally effective in the treatment of primary hypothyroidism, although as a treatment for autoimmune disease it takes more time to see the positive results. The patient's condition will be monitored and treatments will be continued until complete normalization of the anti-TPO levels.

\section{SOURCES OF FUNDING}

None.

\section{CONFLICT OF INTEREST}

None.

\section{ACKNOWLEDGMENT}

None.

\section{REFERENCES}

[1] Hershman JM; Hypothyroidism; 2019 [www.msdmanuals.com]

[2] Holm G; Primary Hypothyroidism; 2019 [www.healthline.com] 
[3] Emerson C, Torres MS; Primary hypothyroidism in adults; 2017 [www.endocrinologyadvisor.com]

[4] Abbate S; The Early Diagnosis and Treatment of Hypothyroidism; Acupuncture Today, Vol 02, Issue 07, 2001

[5] Burke D; Antithyroglobulin Antibody Test; 2017 [www.healthline.com]

[6] Arsovska B, Zhu J, Kozovska K; Case Report: Acupuncture Treatment for Hypothyroidism; Imperial Journal of Interdisciplinary Research (IJIR) Vol-2, Issue-5, 2016

[7] Panthi S, Gao T; Diagnosis and management of primary hypothyroidism in Traditional Chinese Medicine (TCM) and Traditional Indian Medicine (Ayurveda); International Journal of Clinical Endocrinology and Metabolism; 2015

[8] Zhu J, Arsovska B, Kozovska K; Case Report: Acupuncture Treatment in Male Patient with Primary Hypothyroidism; International Journal of Research - Granthaalayah, 7(3) 217-220; 2019

[9] VHA Office of Patient Centered Care and Cultural Transformation; WHOLE HEALTH: CHANGE THE CONVERSATION, Hypothyroidism, Clinical Tool; 2019 [www.projects.hsl.wisc.edu] 